Article

\title{
Sensitivity Study of WRF Simulations over Tanzania for Extreme Events during Wet and Dry Seasons
}

\author{
Abubakar Lungo ${ }^{1} \mathbb{D}$, Sangil Kim ${ }^{2, *}$, Meiyan Jiang ${ }^{2}$, Giphil Cho $^{3}$ and Yongkuk Kim ${ }^{4}$ \\ 1 Central Forecasting Office, Tanzania Meteorological Agency, Dar es Salaam 16103, Tanzania; \\ abubakar.lungo@meteo.go.tz \\ 2 Department of Mathematics, Pusan National University, Busan 46241, Korea; meeyeon126@gmail.com \\ 3 Finance-Fishery·Manufacture Industrial Mathematics Center on Big Data, Pusan National University, \\ Busan 46241, Korea; giphil@pusan.ac.kr \\ 4 Department of Mathematics, Kyungpook National University, Daegu 41566, Korea; yongkuk@knu.ac.kr \\ * Correspondence: sangil.kim@pusan.ac.kr; Tel.: +82-51-510-2209
}

Received: 29 March 2020; Accepted: 30 April 2020; Published: 2 May 2020

check for updates

\begin{abstract}
Precipitation prediction is important to help mitigate the effects of drought and floods on various social and economic activities. This research is to improve the forecasting skill over Tanzania by providing suitable combinations of physical parameterization schemes and horizontal grid spacing of the Weather Research Forecasting (WRF) model for daily forecasting over Tanzania. The performance of different schemes on the precipitation systems during the wet and dry seasons over Tanzania is evaluated such that the sensitivity tests was performed for the WRF model at different horizontal resolutions, and for different physical parameterization schemes (convective and cloud microphysics). The results showed that the improved grid spacing was better at completing forecasts during the wet season, but had little significant impacts during the dry season. Model simulations with combinations of Lin et al. microphysics and the multiscale Kain-Fritsch scheme showed greater success during the both seasons; therefore, these combinations were recommended for Tanzania to resolve weather systems during the wet and dry season simulations, respectively.
\end{abstract}

Keywords: heavy rainfall; precipitation forecasting; wet season; dry season; precipitation forecasting; WRF Model; Tanzania

\section{Introduction}

Rainfall is an important climate phenomenon that affects social and economic activities in Tanzania. The economy of Tanzania is mainly dependent on rain-fed agriculture, which is highly vulnerable to the amount and distribution of rainfall [1]. On the other hand, excessive rainfall also has a negative influence on socioeconomic activities in Tanzania, as it can lead to flooding, loss of life, and damage to properties. In Tanzania, rainfall has large temporal and spatial variability [2]. Therefore, accurate forecasting is necessary. The Tanzania Meteorological Agency (TMA) is a government agency that acts as the country's authoritative voice for weather and climate-related issues. Among the major responsibilities of the TMA is to provide weather forecasts at all scales to the public.

In order to issue forecasts, Tanzania uses numerical weather prediction (NWP) products provided by global centers obtained through the WMO's Severe Weather Forecasting Demonstration Project (SWFDP), namely GFS (Global Forecasting System, USA), ECMWF (European Centre for Medium-Range Weather Forecasts, European countries), and UKGM (United Kingdom Global Model, United Kingdom). The TMA also has access to NWP products from other global centers, including the Unified Model (UM) of Korea and ARPEGE of Meteo-France. There are also regional centers that provide model products to other countries, including Tanzania. These include the UM from the RSMC in Pretoria, South Africa; 
Aire Limitée Adaptation dynamique Développement InterNational (ALADIN) from the Regional Specialized Meteorological Centre (RSMC) for tropical cyclones in the Southwest Indian Ocean in Réunion, France; and WRF from the RSMC in Nairobi, Kenya. At the national level, the TMA also runs a number of regional models, including WRF, Consortium for Small-scale Modeling, and WaveWatch III. As the country is located in a tropical region, the main type of precipitation that affects Tanzania is convective precipitation. This includes showers, thundershowers, hailstones, and sometimes tornadoes or waterspouts. The convective precipitation in the tropics is sometimes difficult to resolve by global models partly because it occurs at small spatial and temporal scales. In order to capture this type of precipitation, an adequate mesoscale model with an appropriate combination of settings is needed. However, most of the rainfall events were not well forecasted by the current global model and regional model. This implies that more suitable numerical model settings are needed to improve the accuracy of the forecasts produced and issued to users and the public.

In this study, the skill of a numerical mesoscale WRF model in forecasting precipitation over Tanzania and the sensitivity of the results of selected physical parameterization schemes and horizontal grid spacing (resolution) during the wet and dry seasons were assessed. Currently, the available settings of the WRF NWP model do not provide accurate forecasts to meet customer satisfaction for all seasons; thus, this research was conducted to improve the quality of the forecast. In addition, following the development and availability of new versions and settings of the WRF system worldwide, this research was conducted to test the sensitivities of the new options for physical parameterization of clouds in the model. This study provided WRF model settings in terms of resolution and physical parameterization schemes (microphysics and cumulus physics) that best resolved weather systems during the wet and dry seasons over Tanzania. The main objective of this study was to simulate and model the rainfall distribution over Tanzania using the WRF model. To achieve this main objective, a number of tasks (specific objectives) were conducted. These included the following: (i) to conduct numerical experiments using the WRF model at different horizontal resolutions and to determine the accuracy of the model, and (ii) to conduct experiments with different physical parameterization schemes (convective schemes and cloud microphysics schemes) to determine the sensitivity of the model.

This paper comprises four sections. Section 1 provides the background of the study area, rationale of the study, and its objectives. Section 2 discusses the research methodology of the study. A description of the domain size experiment and evaluation of different physical schemes are indicated in this section. Section 3 describes the results of the study following the sensitivity tests of the model performance of different physical schemes in forecasting rainfall events. Section 4 includes the summary and remarks and provides recommendations for further studies.

\section{Materials and Methods}

\subsection{Study Area}

Tanzania is an East African nation covering $947,303 \mathrm{~km}^{2}$ that is located between $1^{\circ} \mathrm{S}$ to $12^{\circ} \mathrm{S}$ and $28^{\circ} \mathrm{E}$ to $42^{\circ} \mathrm{E}$ in Figure 1a. Because Tanzania is located in a tropical area, the weather is more controlled by precipitation than by temperature and surface wind, which do not vary much throughout the year. As Tanzania is located in an equatorial climatic region, it often receives a large amount of precipitation during the wet season (October to May) and during the dry season (June to September) each year. Tanzania's rainfall pattern is divided into two types, namely bimodal rainfall pattern areas (areas receiving two rainfall seasons in one year) and unimodal rainfall pattern areas (areas receiving one rainfall season in one year) in Figure $1 \mathrm{~b}$. In the bimodal areas, there is a short rainfall season from October to December and a long rainfall season from March until May each year, while in unimodal areas there is one long rainfall season from November to May each year. 

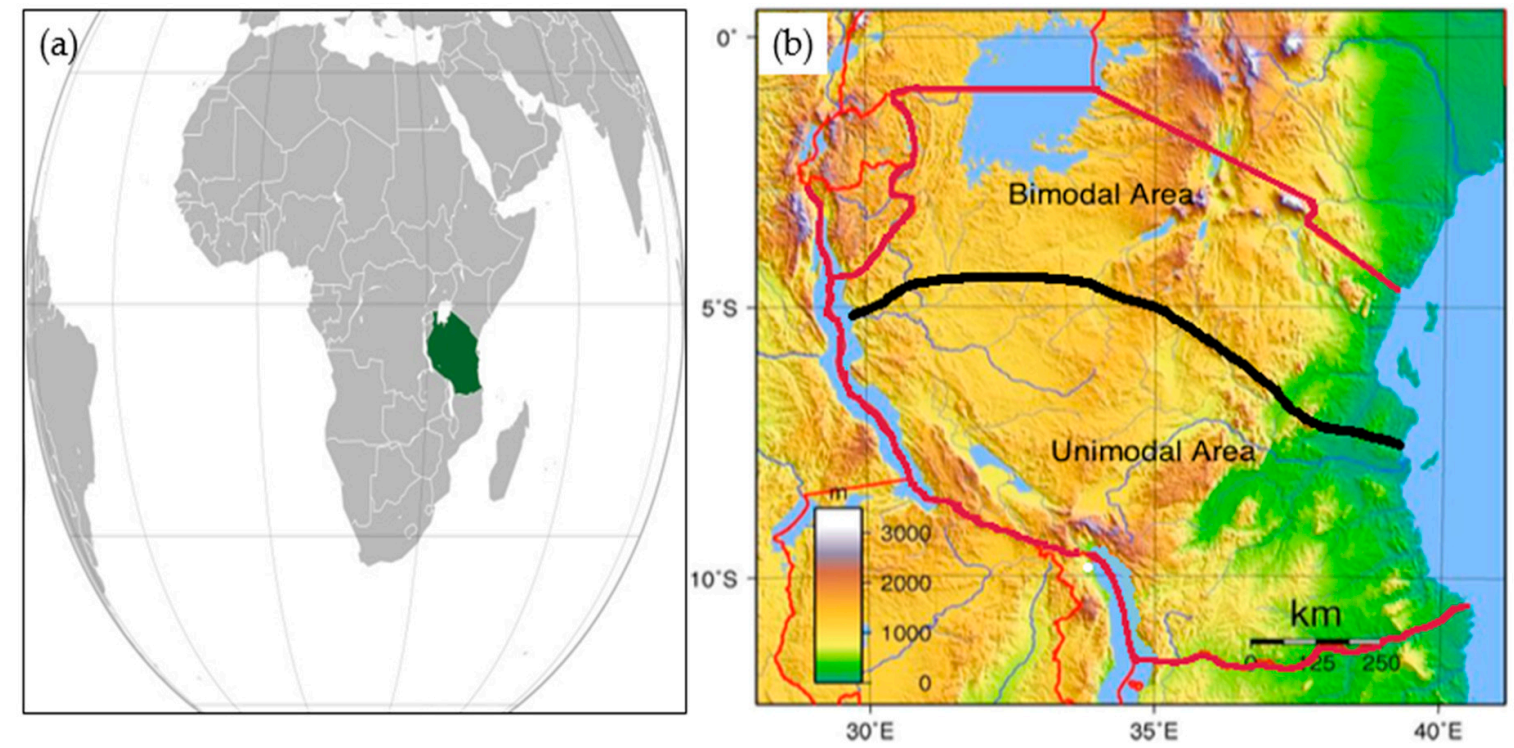

Figure 1. Location of Tanzania in Africa (Image source: citiesandplaces.com) (a) and the rainfall zone in Tanzania (b).

For the wet season, the cases selected for this study included the heavy rain season of 20-22 December 2011. These were very heavy rainfall events due to strengthening of the inter tropical convergence zone (ITCZ), which is the main rainfall mechanism in the country. It is difficult to predict the onset and location of heavy rainfall events caused by the ITCZ, and most of the available global models were unable to correctly resolve the rainfall. For the dry season, the events of 22-25 July 2014 were used. In this month, although it is drier and cooler in Tanzania, the coastal locations receive prolonged periods of light rainfall due to easterly waves and ridging high-pressure systems. The elevated areas and mountainous areas also normally receive precipitation during this month. These rains are always stratiform in nature, which results from layered clouds, such as stratus, stratocumulus, and altostratus or nimbostratus clouds.

\subsection{Rainfall Events and Their Observations}

Rainfall events include 20-22 December 2011 for the wet season and 22-25 July 2014 for the dry season.

\subsubsection{Heavy Rain Event of 20-22 December 2011}

During this heavy rain event, the well-established ITCZ was the dominant weather system. Several locations in the country received heavy rainfall due to the ITCZ. Most of the available global models and the national WRF model of the 19th 0000Z forecasts for these three days showed almost no sign of heavy precipitation over the coastal and central regions, and they forecasted less precipitation over the southern sector of the country. The 24-h forecast issued by the TMA expected only light showers for 20 December 2011. Figure 2a shows satellite images that indicated deep convective clouds along the coastal, central, western, and northern areas of Tanzania [3]. During this period, the Northern Hemisphere high-pressure cells, namely the Azores and the Arabian ridge, remained intense. The southern hemisphere high-pressure cells, namely Mascarene and St. Helena shown in Figure $2 b, c$, were relatively weak. This resulted in southward movement of the ITCZ towards Tanzania. 

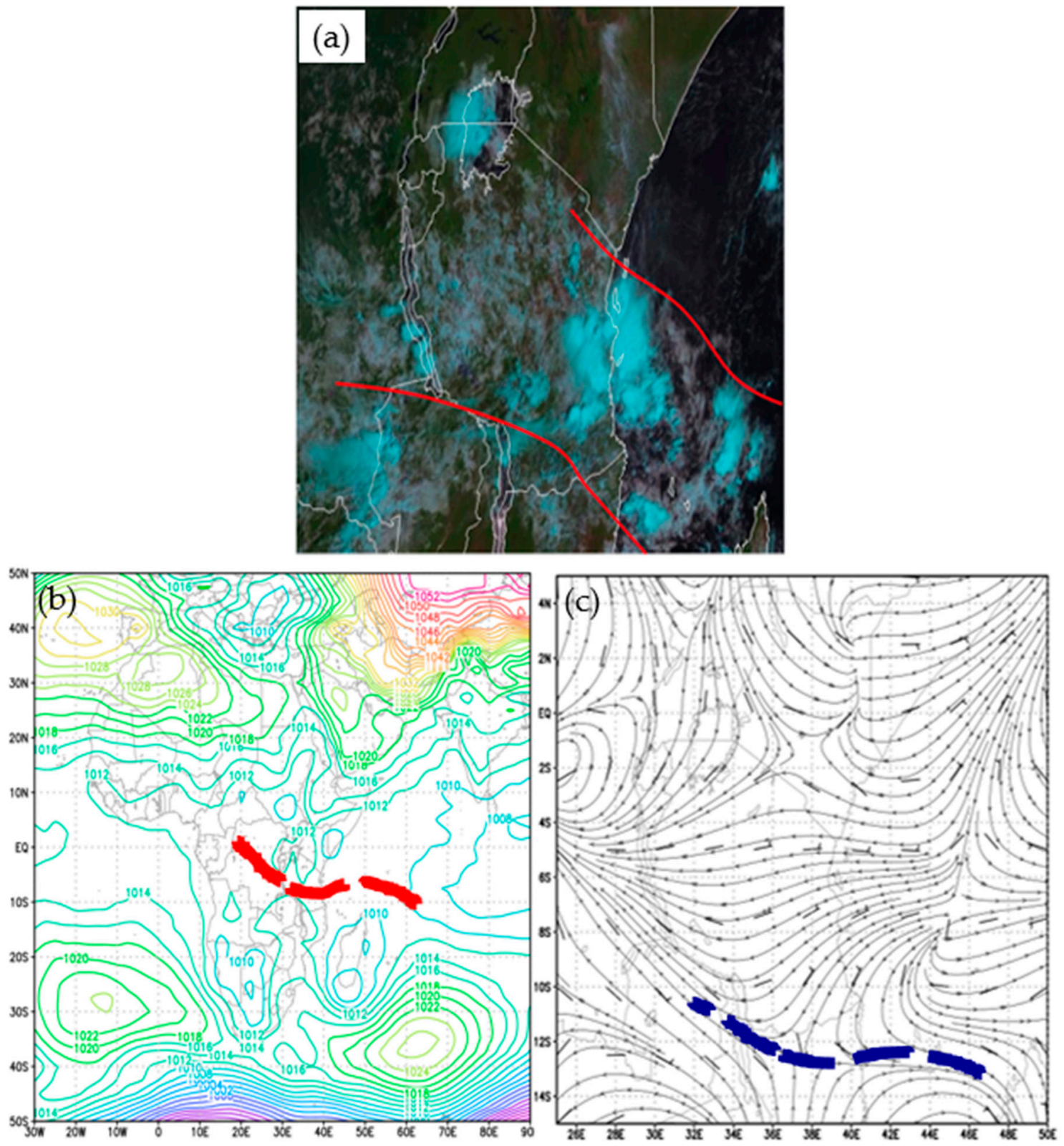

Figure 2. (a) Day natural color RGB (VIS0.6 VIS0.8 VIS1.6) satellite imagery of Eastern Africa at 07:12UTC of 21st December 2011 showing cloud development zone (indicated in red) indicating the presence of the inter tropical convergence zone (ITCZ) (Image source: EUMETSAT); (b) MSLP pattern on 20-22 December 2011 showing a low-pressure area (red dashed line) over Tanzania; and (c) $700 \mathrm{hPa}$ mean wind-flow pattern on 20-22 December 2011 showing the location of the inter tropical convergence zone (blue dashed line) over Tanzania. (Images source: NCEP Reanalysis Data).

\subsubsection{Rain Event of $22-25$ July 2014}

For this event, the dominant weather system was the ridging high. A ridging high is a weather system that occurs in southeastern Africa when the region is dominated by a high-pressure system from the south that extends the ridge northward along the coast, as shown in Figure 3. Normally, a ridging high is a low-level system and appears during the Southern Hemisphere's winter (dry season in most areas). It is considered one of the off-season rainfall mechanisms. In most cases, ridging highs are associated with strong maritime (moist) low-level winds as the high-pressure systems are situated behind the frontal system, thereby causing a strong pressure gradient and strong winds. As these strong, moist, low-level winds encounter topographic barriers due to the nature of the topography of 
southeastern Africa, they deposit a large amount of moisture just before the topographic barriers; as the area is dominated by the high-pressure system, a cluster of low-level stratiform (layered clouds) clouds forms and results in light rainfall that can last for a prolonged period of time, such as an entire day, and causes flooding on the ground. The EUMETAST satellite imagery indicates the presence of clusters of layered clouds oriented north-south along the East African coast advected from the east over the Indian ocean (image not shown). The presence of layered clouds advected from the east indicates the easterly wave pattern [4]. The synoptic-scale mean sea-level pressure analysis showed that the area was dominated by the ridge (high pressure) and the cold, dry southerly flow, thereby indicating that the clouds were layered (stratiform).

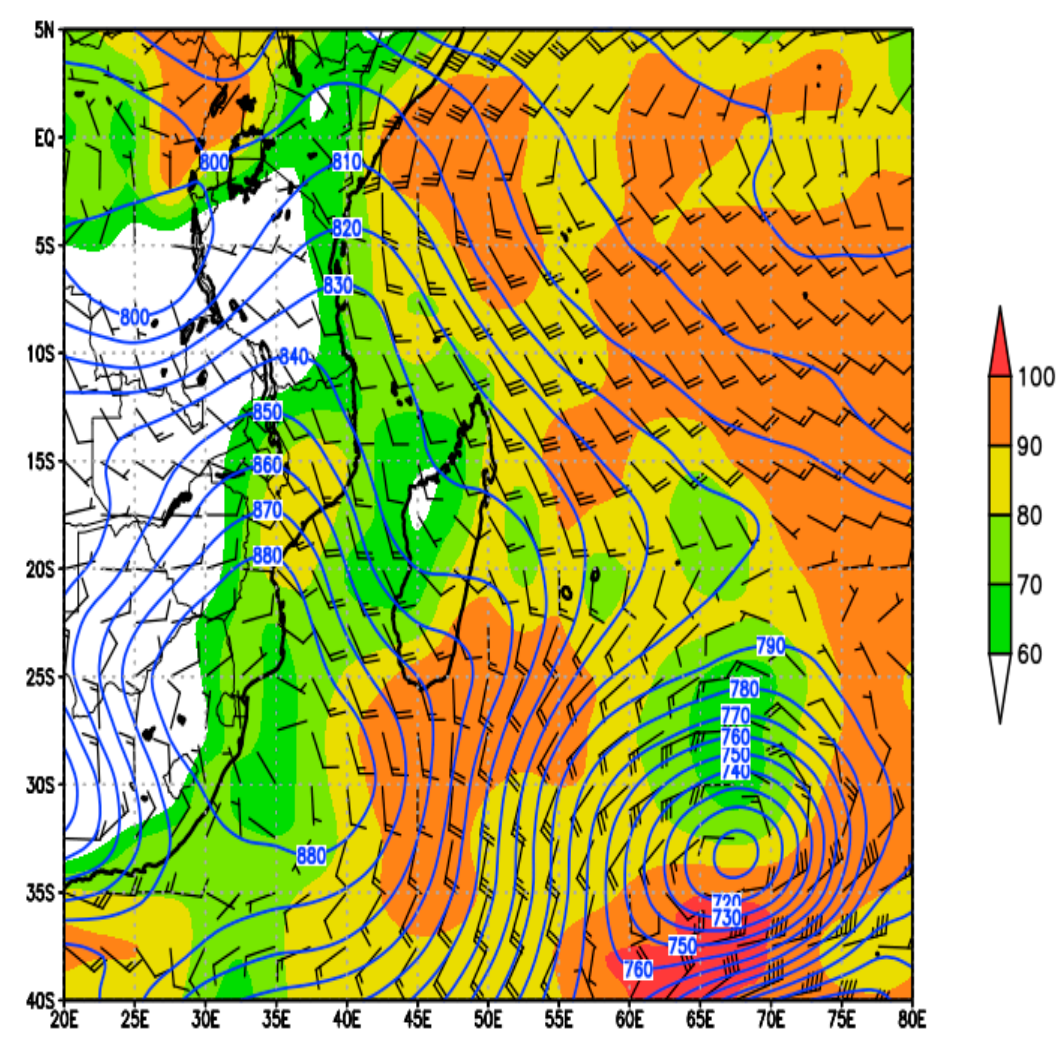

Figure 3. Map of the southern area of Africa showing $925 \mathrm{hPa}$ geopotential height pattern overlaid on wind $(\mathrm{KT})$ and relative humidity $(\mathrm{RH})$ fields portraying the ridging high-pressure system on 22 July 2014. The colorbar represents RH (Image generated with GrADS using NCEP Reanalysis Data).

\subsubsection{Observations}

During the events described in previous subsections, the daily rainfall data have been observed by the TMA's station network in Figure 4. These data were observed from both automatic and manned stations. The data contained 24-h accumulated rainfall data as observed at 06:00 UTC on each of the event days. The station observational data were considered the most accurate available data for the case selection and for the verification of the forecasts by the WRF model in this study. Therefore, the rainfall accumulation data from a total of 42 stations were used for the verification of the model performance. 


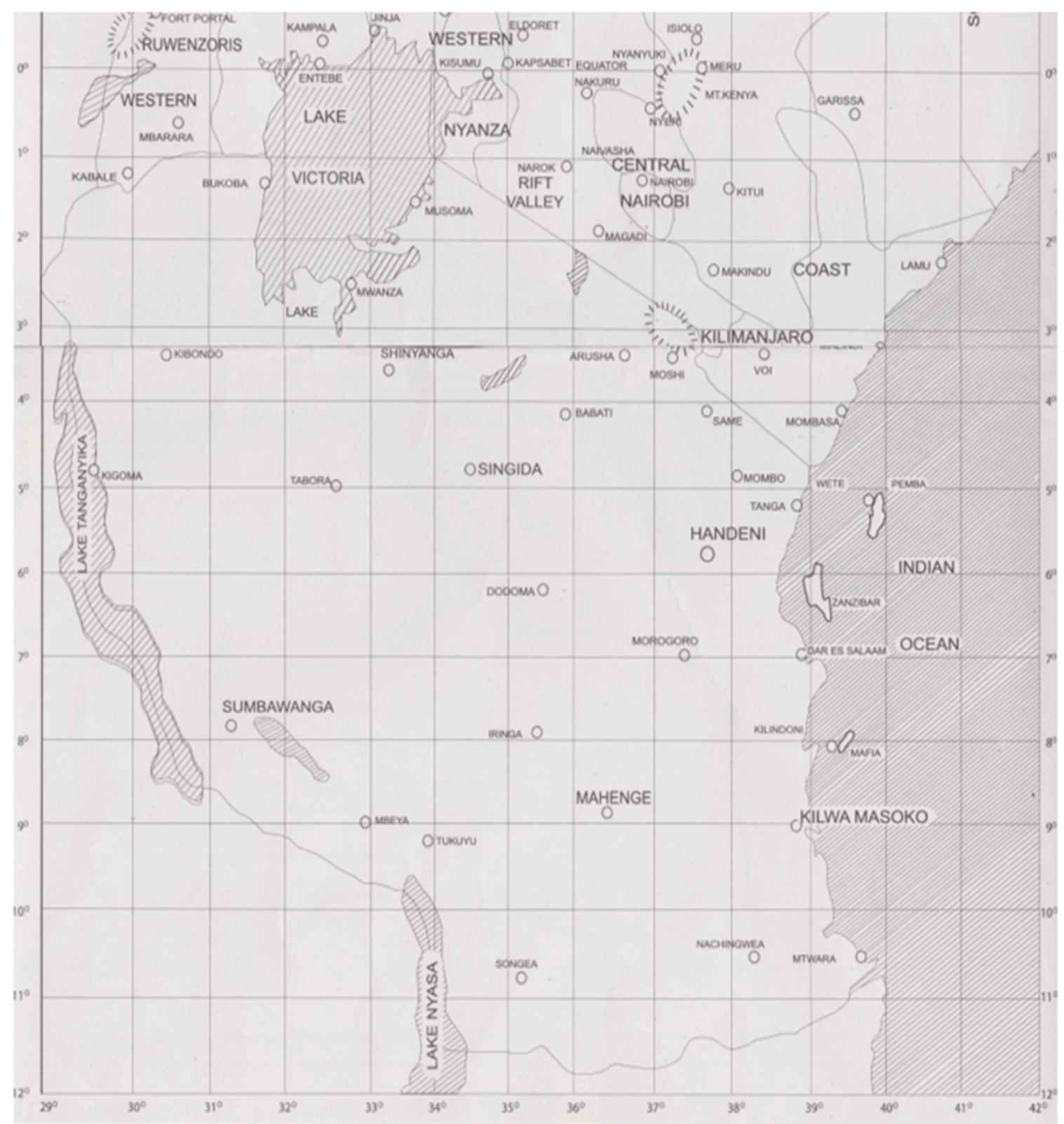

Figure 4. The Tanzania Meteorological Agency (TMA)'s station network. The circles indicate the locations of both automatic and manned stations. (Image source: Tanzania Meteorological Authority).

\subsection{Default Model Configuration}

At the TMA central forecasting office, WRF model version 3.8.1 [5] was configured for East Africa and the Lake Victoria Basin. The domain was configured in the Mercator map projection with a central latitude of $10^{\circ} \mathrm{S}$ and longitude of $36^{\circ} \mathrm{E}$. It had a one-way nested domain configuration consisting of an outer domain with $15 \mathrm{~km}$ resolution as shown in Figure $5 \mathrm{a}$, and an inner domain with $5 \mathrm{~km}$ resolution, as shown in Figure 5b. The outer domain and inner domain had $200 \times 200$ and $235 \times 160$ grid points, respectively. Both had 32 vertical levels with a maximum height of $100 \mathrm{hPa}$. Also, in order for the mesoscale model to run, the initial and boundary condition data were needed. GFS initial and boundary condition data were downloaded from the NOAA Global Model GFS and were used to initialize the mesoscale WRF model in this study. 


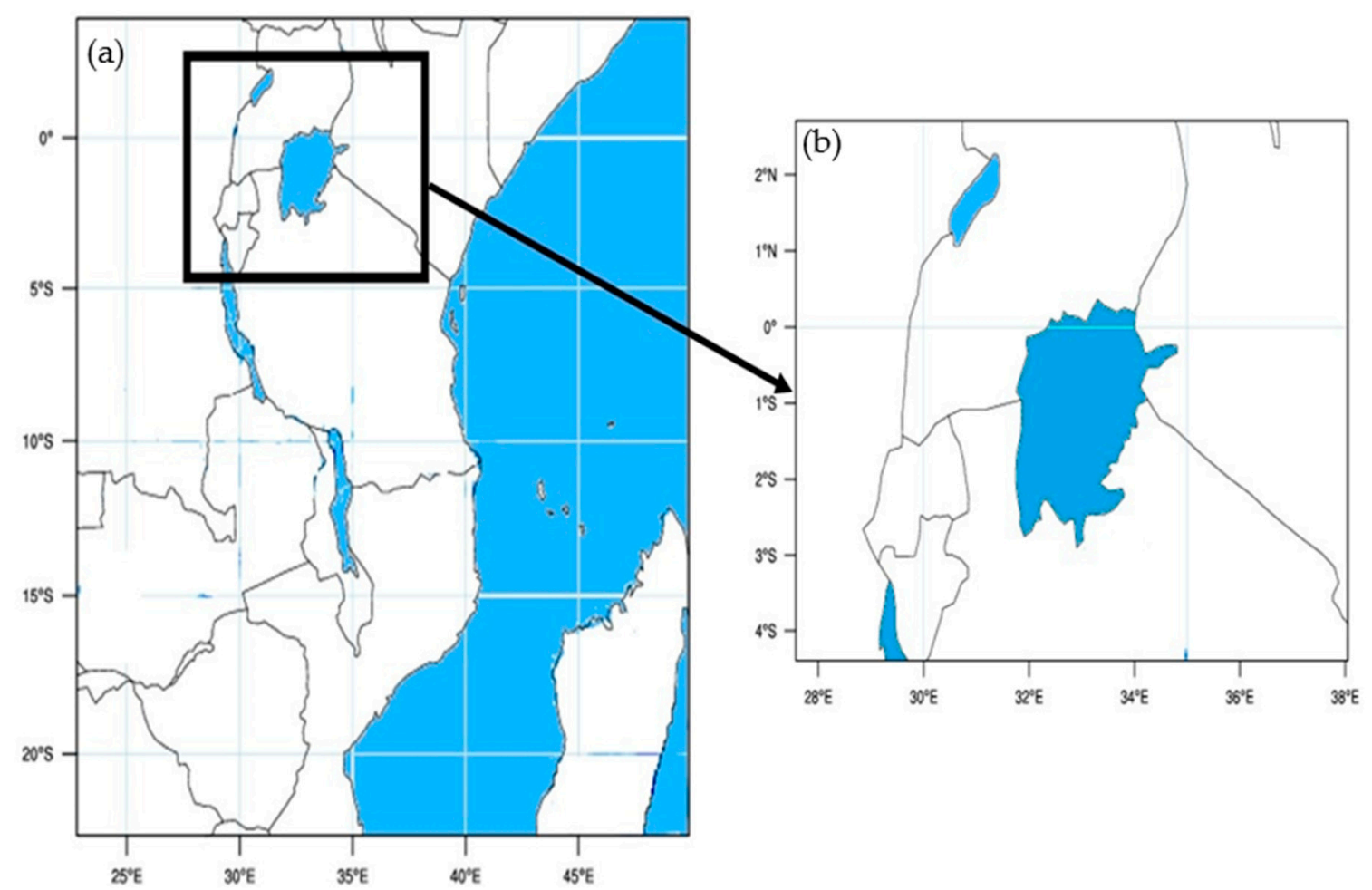

Figure 5. (a) Domain 1 (the outer domain); (b) Domain 2 (the inner domain, as indicated by the black rectangle in domain 1$)$.

For physical parameterization, the default model used the same configuration that is utilized by the WRF-ARW model run by the TMA, Tanzania. The physical parameterization included the multiscale Kain-Fritsch cumulus physics [6,7], YSU scheme for planetary boundary layers (PBL) [8], Lin et al. [9] cloud microphysics, the Unified Noah land surface model [10], and RRTM [11] schemes for shortwave and longwave radiation, respectively. Table 1 summarizes the default model configuration. The initial and boundary conditions for the domain were obtained from the GFS global model [12] with 0.5 degree horizontal resolution.

Table 1. Default model configuration and physical parameterization.

\begin{tabular}{|c|c|c|}
\hline Configuration & Outer Domain & Inner Domain \\
\hline WRF model version & \multicolumn{2}{|c|}{3.8 .1} \\
\hline Horizontal grids & $200 \times 200$ & $235 \times 160$ \\
\hline Grid spacing $(\mathrm{km})$ & 15 & 5 \\
\hline Vertical grid & \multicolumn{2}{|c|}{32 layer/top $100 \mathrm{hPa}$} \\
\hline Integration time (s) & 90 & 30 \\
\hline Radiation physics & \multicolumn{2}{|c|}{$\begin{array}{l}\text { RRTM scheme for long wave radiation and Goddard scheme for } \\
\text { shortwave radiation }\end{array}$} \\
\hline Cloud microphysics & \multicolumn{2}{|c|}{ Lin et al. scheme } \\
\hline Surface layer physics & \multicolumn{2}{|c|}{ Revised MM5 Monin-Obukhov scheme } \\
\hline Land surface physics & \multicolumn{2}{|c|}{ Unified Noah LSM } \\
\hline Planetary boundary layer & \multicolumn{2}{|c|}{ YSU scheme } \\
\hline Land use and topography data & \multicolumn{2}{|c|}{$30 \mathrm{~s} / \mathrm{USGS}$} \\
\hline Cumulus physics & Multiscale Kain-Fritsch scheme & N/A \\
\hline Initial condition & \multicolumn{2}{|c|}{$\begin{array}{l}\text { Global Forecasting System model forecast fields } \\
\qquad(50 \mathrm{~km} \text { resolution, NCEP) }\end{array}$} \\
\hline
\end{tabular}




\subsection{Experimental Model Configuration}

The experimental model configuration used was the same configuration as the control settings, except for the grid spacing, cloud microphysics, and cumulus physics. Table 2 summarizes the experimental model configuration, and research design configuration. Apart from the $15 / 5 \mathrm{~km}$ outer and inner domain resolution, there were also $12 / 4 \mathrm{~km}$ resolution and $9 / 3 \mathrm{~km}$ resolution for outer and inner domains. For each model resolution, the cloud microphysics and cumulus physics schemes were comprised of seven different experimental configurations including the default model configuration in Table 1 such that the Kessler and WRF double-moment 6-class [13] were used for microphysics schemes and the Betts-Miller-Janjic [14], ensemble Grell [15,16], and new simplified Arakawa [17] schemes were used for the cumulus physics schemes. Note that for each rainfall event, there were a total of 21 runs seen in Table 2, and that the simulation 1 has the same model configuration of the default seen in Table 1 . There are various parameterization schemes for microphysics including the WRF single-moment 5-class microphysics [18], single-moment 6-class microphysics [19], and cumulus parameterizations including old simplified Arakawa-Schubert [20], Tiedtke [21], new Tiedtke [22], and multiscale KF [23]. However, there are too many combinations to investigate, so we only considered selected the combinations that we are interested in.

Table 2. Experimental summary of sensitivity studies for resolution, microphysics, and cumulus physics. The configuration of simulation 11 is the same as that of the default model seen in Table 1.

\begin{tabular}{cccc}
\hline Experiment & $\begin{array}{c}\text { Resolution of Outer/Inner } \\
\text { Domains } \mathbf{( k m )}\end{array}$ & Microphysics Scheme & Cumulus Physics Scheme \\
\hline Simulation 11(default) & & Lin et al. & Multiscale Kain-Fritsch \\
Simulation12 & WDM6 scheme & Betts-Miller-Janjic scheme \\
Simulation 13 & Kessler scheme & Betts-Miller-Janjic scheme \\
Simulation 14 & WDM6 scheme & Ensemble Grell scheme \\
Simulation 15 & Kessler scheme & Ensemble Grell scheme \\
Simulation 16 & WDM6 scheme & New simplified Arakawa \\
Simulation 17 & Kessler scheme & New simplified Arakawa \\
\hline Simulation 21 & Lin et al. & Multiscale Kain-Fritsch \\
Simulation 22 & WDM6 scheme & Betts-Miller-Janjic scheme \\
Simulation 23 & Kessler scheme & Betts-Miller-Janjic scheme \\
Simulation 24 & WDM6 scheme & Ensemble Grell scheme \\
Simulation 25 & Kessler scheme & Ensemble Grell scheme \\
Simulation 26 & WDM6 scheme & New simplified Arakawa \\
Simulation 27 & Kessler scheme & New simplified Arakawa \\
\hline Simulation 31 & & Lin et al. & Multiscale Kain-Fritsch \\
Simulation 32 & & WDM6 scheme & Betts-Miller-Janjic scheme \\
Simulation 33 & & Kessler scheme & Betts-Miller-Janjic scheme \\
Simulation 34 & WDM6 scheme & Ensemble Grell scheme \\
Simulation 35 & & Kessler scheme & Ensemble Grell scheme \\
Simulation 36 & WDM6 scheme & New simplified Arakawa \\
Simulation 37 & & Kessler scheme & New simplified Arakawa \\
\hline
\end{tabular}

\subsection{Analysis Procedure}

To assess the skill of the model, contingency tables and the associated scores were used to represent the relationship between the forecasted and observed rainfall [24]. This technique consisted of a two-dimensional contingency table that displayed the discrete joint distribution of the forecasted and observed events in terms of their frequency of occurrence. In order to create the contingency table, a threshold value was first determined; this value had to be exceeded by the observation or the forecast for it to be termed as an event. Once each value of the data set was classified as an event or nonevent, they were distributed according to the intersection between forecast and observation, as indicated in Table 3. 
Table 3. Contingency table. Threshold for the wet and the dry seasons is $10 \mathrm{~mm}$ and $1 \mathrm{~mm}$, respectively.

\begin{tabular}{ccc}
\hline \multirow{2}{*}{ Forecast } & \multicolumn{2}{c}{ Observed Rainfall Exceeding Threshold Value } \\
\cline { 2 - 3 } & Yes & No \\
\hline Yes & Hit & False alarm \\
\hline No & Miss & Correct Rejection \\
\hline
\end{tabular}

From Table 3, the following indexes were calculated to assess the scores of the experiments. These included probability of detection (POD), frequency bias (BIAS), proportion correct (PC), threat score (TS), and false alarm ratio (FAR), which was calculated using the following formulas:

$$
\begin{gathered}
\mathrm{POD}=\frac{\text { hit }}{\text { hit }+ \text { miss }}, \mathrm{BIAS}=\frac{\text { hit }+ \text { false alarm }}{\text { hit }+ \text { miss }}, \\
\mathrm{PC}=\frac{\text { correct rejection }}{\text { hit }+ \text { miss }+ \text { false alarm }+ \text { correct rejection }}, \\
\mathrm{TS}=\frac{\text { hit }}{\text { hit }+ \text { false alarm }+ \text { miss }}, \mathrm{FAR}=\frac{\text { false alarm }}{\text { hit }+ \text { false alarm }}
\end{gathered}
$$

POD, also known as hit rate, is a statistical measure that examines events by measuring the proportion of observed events that were correctly forecasted. It ranges between 0 and 1 , whereby 0 represents poor skill and 1 represents perfect skill. BIAS is another statistical measure that compares the frequency of forecasts (forecasted yes) to the frequency of actual occurrences (observed yes). It ranges between 0 and infinity, whereby 1 represents unbiased, BIAS $>1$ represents over-forecasting, and BIAS $<1$ represents under-forecasting. PC gives the fraction of all forecasts that were correct. It is sensitive to both hits and correct rejections. The value ranges between 0 and 1 and the perfect score is 1 . TS, also known as the critical success index (CSI), is a statistical index that is widely used as a performance measure of rare events (e.g., rainfall). It ranges between 0 and 1 , whereby TS $=1$ represents perfect skill and TS $=0$ represents poor skill. FAR gives the fraction of forecast events that were observed to be nonevents. The value varies between 0 and 1 and the perfect score is 0 .

In order to compare the performance of different model configurations, the combined skill score was employed [25]. Such a skill score plays a role in summarizing the above statistical scores that could be used together when there are many model results for different experiments, and the concept of such skill scores gives the readers overall evaluation and direct understandings of all statistical scores. Thus, we slightly modified the combined skill score such that a modified skill score employed the following scores: PC, POD, TS, and FAR. The purposes of the modified skill score below help us to understand the overall performance better and summarize the results for a final decision.

$$
\text { Combined score }=\text { mean }\{\mathrm{PC}+\mathrm{POD}+\mathrm{TS}+(1-\mathrm{FAR})\}
$$

where the values of PC, POD, and TS are always positive and range between 0 and 1 . The FAR range is also between 0 and 1 . Thus, the result of 1-FAR is always positive and between 0 and 1 . Thus, by its definition, the modified skill score above always ranges between 0 and 1 . Note that the statistical skill scores are used here to assess overall performance in order to determine the best model configurations. To summarize all of the model performance results, we utilized the Taylor diagram for the combined skill score and FB to represent the overall performance of the model rainfall predictions [26].

\section{Numerical Results}

The section below describes the numerical results for model horizontal resolution and physical parameterization. To do so, we first show the Taylor diagram to evaluate the overall performances for all 21 simulations in Table 2. Then, we analyze the detailed results for the model horizontal resolution and then the effects on physical parameterization. Note that we only show the results with the threshold for an event of $10 \mathrm{~mm}$ or above for the wet season and $1 \mathrm{~mm}$ or above for the dry season. 
Figure 6 shows the results of the combined score and BIAS for the wet season and the dry season, respectively. Note that the blue contour is related to the azimuthal angle, and the black dashed contours are the radial distance from the origin. Hence, when the model agrees with observations, both values of the combined score and BIAS for the models lie nearest to 1 . The diagram for the different resolution and physical parameterization schemes indicated that models with the same resolution with different physics showed different performances for both seasons, and predicted differently for the two seasons. However, it is still notable that the square $(9 / 3 \mathrm{~km}$ resolution) and triangle $(15 / 5 \mathrm{~km}$ resolution) shapes are located closest to the value of 1 . In addition, it showed relatively good skill scores of the models with colors of black, magenta, and yellow, respectively corresponding to the physics scheme for simulations 1,4 , and 7 .
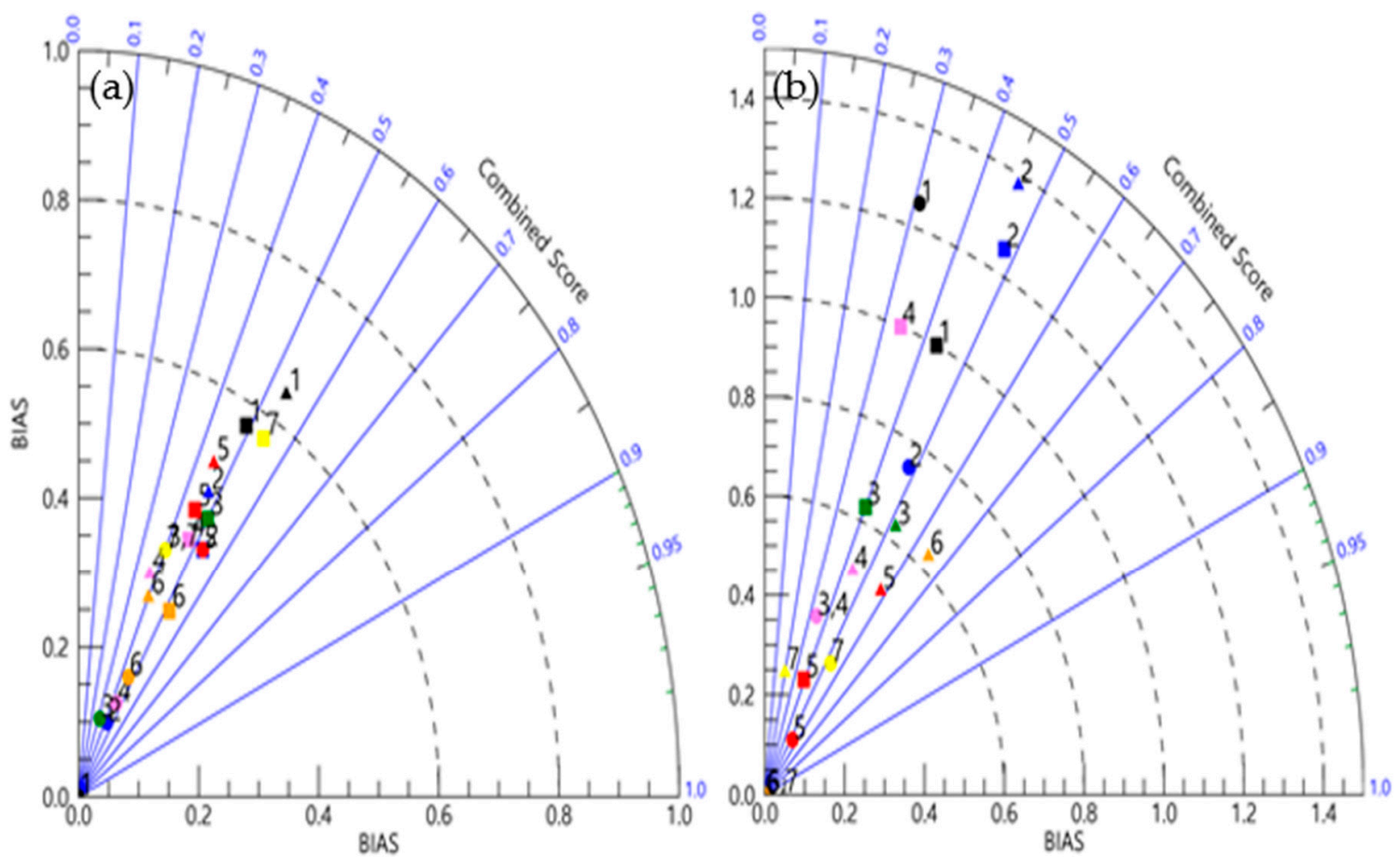

Figure 6. Taylor diagram displaying combined skill score and BIAS for (a) wet season and (b) dry season. The shapes of square, circle, and triangle represent the resolution of $9 / 3 \mathrm{~km}, 12 / 4 \mathrm{~km}$, and 15/5 km, respectively. The numbers with colors of black, blue, green, magenta, red, orange, yellow in order represent simulations using the same physical parameterization from the simulation 1 to simulation 7 . The blue contour represents the azimuthal angle, and the black dashed contour is the radial distance from the origin.

To show more details for model performances, in Figure 7 we showed the combined score and BIAS for different resolutions in both wet and dry seasons. Combined scores showed that the models with the high resolution showed relatively better performances during both seasons, while during the dry season, the models with the coarsest resolution also showed good performance. The model BIAS score indicates whether the models systematically favor producing precipitation. Among different combinations of model physical parameterizations, the BIAS for the models with multiscale Kain-Fritsch cumulus physics together with Lin et al. microphysics showed comparatively more accurate scores than others for both seasons. Overall, according to the Taylor diagram and the statistical skill scores of the model simulations for both wet and dry seasons, it was clear that the model outputs with the finest resolution showed predictability that is more acceptable. 

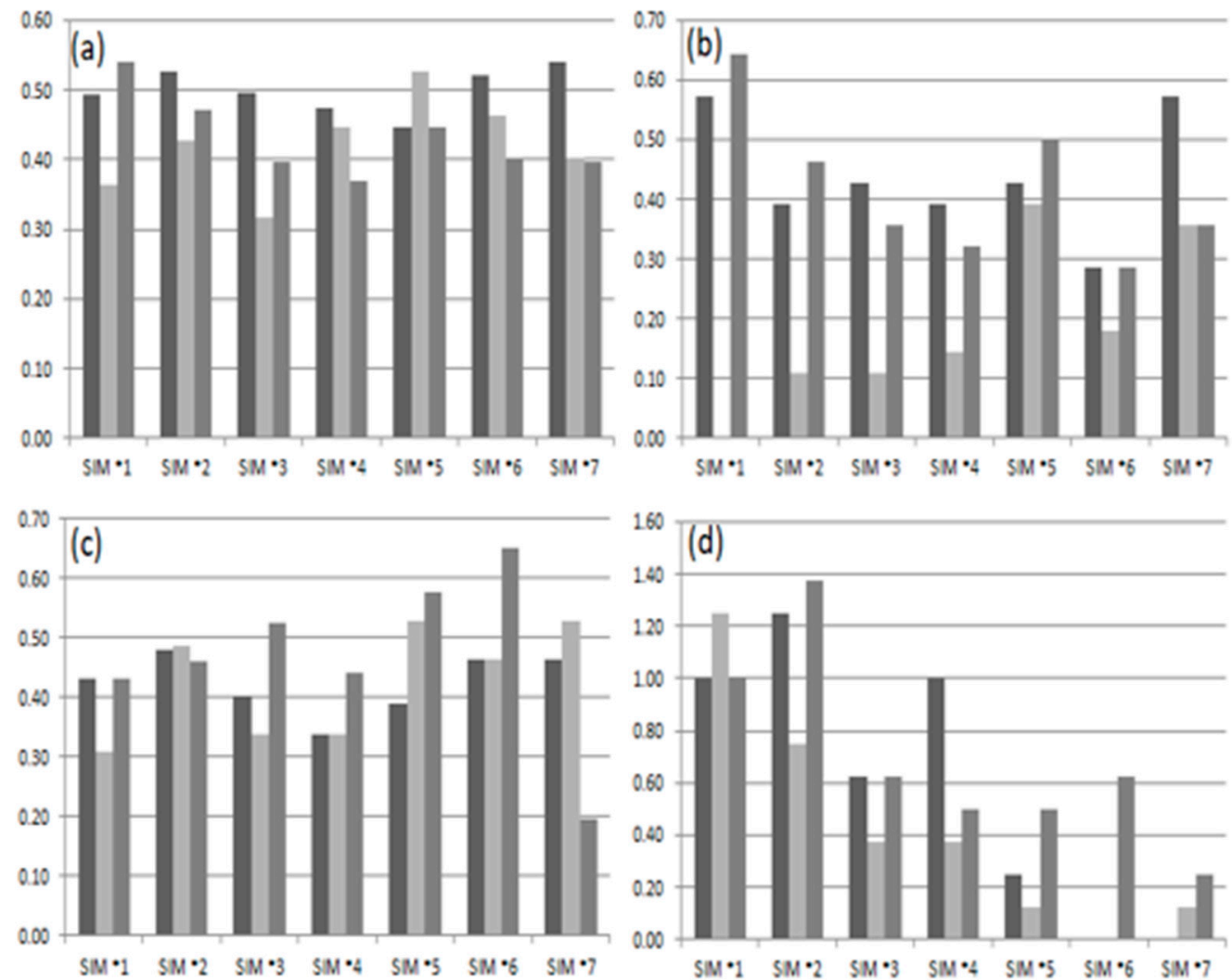

Figure 7. Combined Skill score $(\mathbf{a}, \mathbf{c})$ and BIAS $(\mathbf{b}, \mathbf{d})$ for the wet season $(\mathbf{a}, \mathbf{b})$ and the dry season $(\mathbf{c}, \mathbf{d})$. Horizontal axes represent the discrete microphysical schemes corresponding to simulation* 1 to simulation*7. The left, middle, and right bars in each experiment $\left(\mathrm{SIM}^{*} 1, \mathrm{SIM}^{*} 2, \ldots, \mathrm{SIM}^{*} 7\right)$ represent the skill score values for resolutions of $9 / 3 \mathrm{~km}, 12 / 4 \mathrm{~km}$, and $15 / 5 \mathrm{~km}$, respectively.

\subsection{Model Resolution Effect}

In this section, we simulated rainfall over Tanzania for both seasons to examine the impact of horizontal grid resolution on model predictability. It is generally assumed that models with higher resolution have higher skill than those with lower resolution in resolving small-scale convective systems. This is because most convective clouds occur at a small horizontal scale ranging from several hundreds of meters to a few kilometers. In this study, this behavior was clearly found for the wet season, but a significant difference was not found for the dry season.

Figure 8 showed that during the wet season, all the resolution settings which were 15/5, 12/4 and $9 / 3 \mathrm{~km}$ grid spacing showed reasonably good forecasts in terms of special coverage of the rainfall systems. Increased resolution especially showed improvements in the special coverage when compared to the low-resolution simulations. This is because during the wet season, when most of the precipitation activities over Tanzania are convective in nature, the horizontal grid spacing improved the skill of the forecast. This behavior was also the case for the other researches [27]. That is, convective systems take place in small areas and are highly influenced by local features like topography and land cover, so the higher resolution models provide better skills in predicting predominant convective weather systems.

For the dry season however, there was no visible pattern regarding the improvement of the skills of the model, as the model resolution was increased over Tanzania, as shown in Figure 9. This may have been due to the fact that during the dry season, most of the precipitation activities were stratiform in nature due to the synoptic-scale systems (ridging high and easterly waves). That is, the weather systems dominating the country during the dry season were mainly stratiform, occupying large areas and insubstantially affected by local features like area topography and land cover. Thus, increased resolution may have little impact in predicting stratiform systems. This is similar to the results of 
the European region [28]. Even though the model resolutions did not show a big difference for predicting rainfall during the dry season, the results indicated a relatively positive effect for the dry season. Overall, analysis of the rainfall predictions from the experiments showed that increasing model resolution had an overall positive impact on rainfall prediction for both seasons.

Note that the precipitation with $15 / 5$, and $9 / 3 \mathrm{~km}$ resolution are alike, while they are different from that with $12 / 4 \mathrm{~km}$. That is, the precipitation locations and their magnitudes are not linearly related to the model resolutions. It is generally known that global models overestimate light precipitation and underestimate heavy rainfall due to the low horizontal resolution compared to the scale of the precipitation core [29]. Also, in some regional studies, the heavy rainfall cores with different resolutions showed slight shifts to different locations and the magnitude of precipitation was underestimated [30,31]. This difference might be the effects of the initial conditions, which are significant for short-range forecasts, and higher forecast skill could be achieved either by generating an initial condition via data assimilation schemes or by expanding the region used for the outer domain. In this study, however, the unknown nonlinearity between model resolution and rainfall core has been not articulated yet, and an improvement in forecast skill should be pursed in a subsequent study.
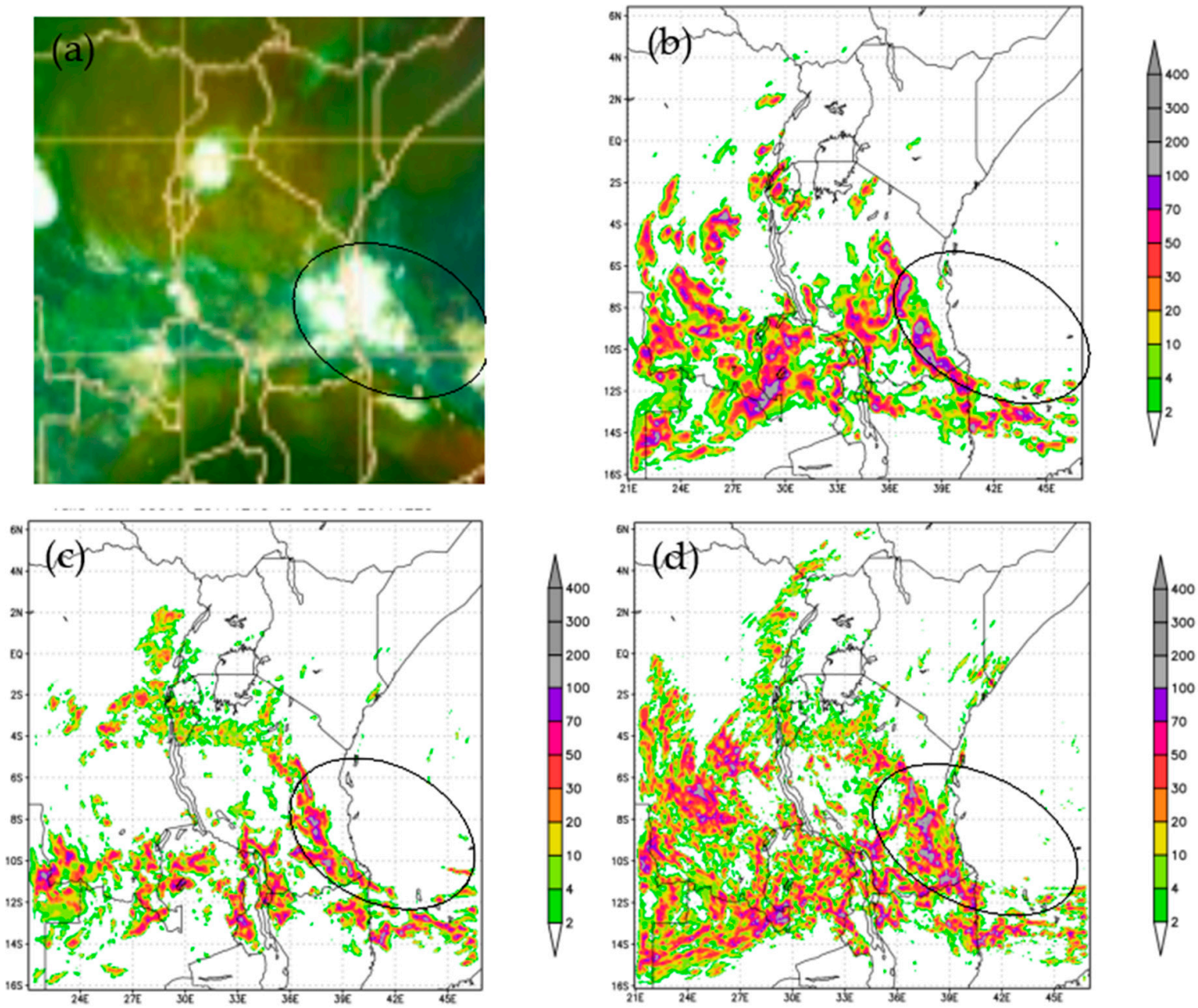

Figure 8. Total precipitation amount during the wet season on 20 December 2011. (a) Satellite observation from airmass RGB (WV6.2-WV7.3, IR9.7-IR10.8, WV6.2) image source: EUMETSAT; and 24-h accumulated model rainfall forecasts for (b) 15/5 km resolution; (c) 12/4 km resolution; (d) $9 / 3 \mathrm{~km}$ resolution. Colorbars represent the total precipitation amount $(\mathrm{mm})$. 

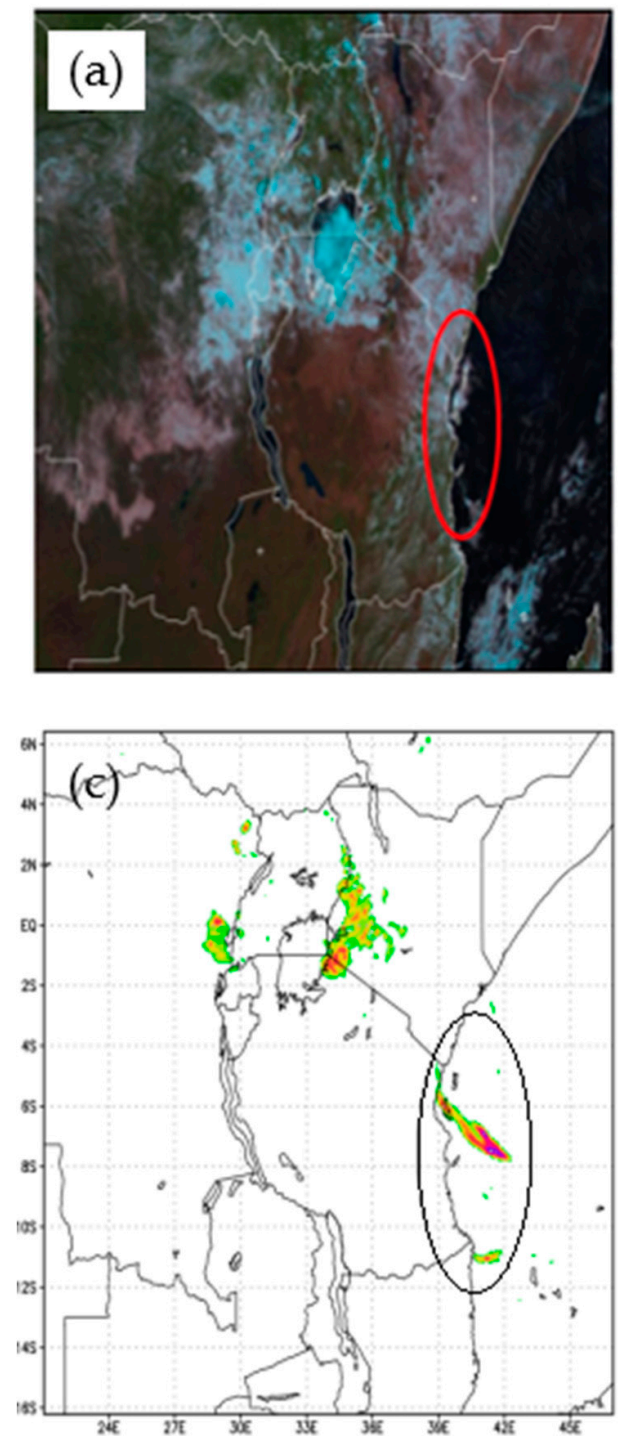
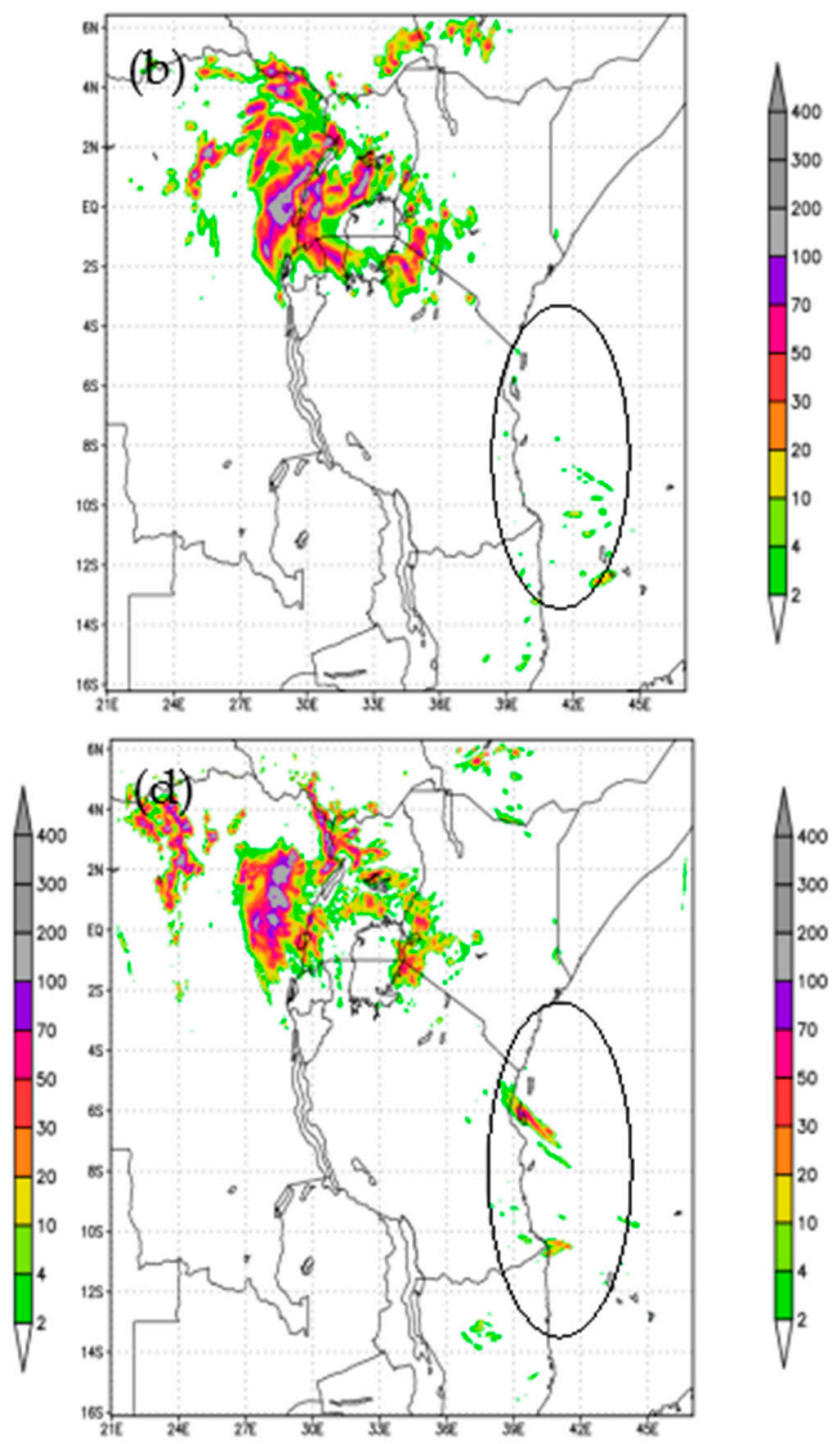

Figure 9. Total precipitation amount for the dry season on 26 July 2014. (a) Day natural color RGB VIS0.6 VIS0.8 NIR1.6 satellite observation at 1015UTC (image source: EUMETSAT); and 24-h accumulated model rainfall forecasts for (b) 15/5 km resolution; (c) $12 / 4 \mathrm{~km}$ resolution; (d) 9/3 km resolution. The colorbar represents the total precipitation amount $(\mathrm{mm})$.

\subsection{Impact on Physical Parameterization}

The statistical evaluation methods, POD, PC, TS, FAR, and BIAS, for rainfall occurrence and amount are very important. In the previous subsection, the models with the finest resolution respectively revealed better and similar rainfall predictability than the model with coarser resolution for the wet and dry seasons. In this section, we evaluated the effect of the physical parameterization for simulation 11 , simulation $12, \ldots$, simulation 17 , the models that were configured with $3-\mathrm{km}$ resolution for the inner domain and 9-km resolution for the outer domain, as shown in Table 2. In order to make the statistical results more significant, we added the 5-8 May 2017 heavy rain event for the wet season and the 20-23 August 2017 rain event for the dry seasons.

Table 4 shows averages of the statistical skill scores for the wet and dry seasons for those simulations indicated by simulation 1 , simulation $2, \ldots$, simulation 7 . For example, POD is a statistical measure that relates the likelihood of detection of the meteorological event by the forecast. It is calculated as the ratio of the number of events forecasted to the total number of forecasts (hit/[hit + miss]). In Table 4, it is evident that for the wet season, the default setting (simulation 1), which was comprised 
of Lin et al. microphysics and multiscale Kain-Fritsch cumulus physics schemes, had the highest POD (0.59), followed by simulation 4 (Kessler microphysics and new simplified Arakawa cumulus physics schemes), which had an average POD of 0.44 . On the other hand, for the dry season, the POD of the events was generally very low. This may have been due to the fact that there were few reports to verify, as most of the stations reported precipitation of less than $1 \mathrm{~mm}$, especially for coastal areas where the number of observation stations is not sufficient. Other statistical scores showed slightly different results such that the highest score of PC, TS, and FAR, and the unbiased one of BIAS for the wet (dry) season was simulation 1 (simulation 5), simulation 1 (simulation 2), simulation 6 (simulations 5,6,7), and simulation 1 (simulation 1), respectively.

Table 4. Average of the statistical skill scores for the wet and dry seasons for each simulation. CS and MDE stand for combined score and mean absolute distance error, respectively. The thick black bold numbers indicate the highest or unbiased scores for statistical skills for each season.

\begin{tabular}{|c|c|c|c|c|c|c|c|c|c|c|c|c|c|c|}
\hline & \multicolumn{7}{|c|}{ Wet Season } & \multicolumn{7}{|c|}{ Dry Season } \\
\hline & $\operatorname{sim} 1$ & $\operatorname{sim} 2$ & $\operatorname{sim} 3$ & $\operatorname{sim} 4$ & $\operatorname{sim} 5$ & $\operatorname{sim} 6$ & $\operatorname{sim} 7$ & $\operatorname{sim} 1$ & $\operatorname{sim} 2$ & $\operatorname{sim} 3$ & $\operatorname{sim} 4$ & $\operatorname{sim} 5$ & $\operatorname{sim} 6$ & $\operatorname{sim} 7$ \\
\hline POD & 0.59 & 0.42 & 0.34 & 0.44 & 0.28 & 0.18 & 0.33 & 0.38 & 0.40 & 0.28 & 0.24 & 0.17 & 0.00 & 0.06 \\
\hline PC & 0.71 & 0.68 & 0.65 & 0.65 & 0.59 & 0.61 & 0.63 & 0.75 & 0.81 & 0.80 & 0.80 & 0.84 & 0.80 & 0.81 \\
\hline TS & 0.28 & 0.22 & 0.16 & 0.18 & 0.09 & 0.10 & 0.13 & 0.13 & 0.20 & 0.13 & 0.12 & 0.14 & 0.00 & 0.05 \\
\hline FAR & 0.25 & 0.15 & 0.18 & 0.24 & 0.33 & 0.00 & 0.28 & 0.63 & 0.48 & 0.56 & 0.56 & 0.00 & 0.00 & 0.00 \\
\hline CS & 0.58 & 0.54 & 0.49 & 0.51 & 0.41 & 0.47 & 0.45 & 0.41 & 0.48 & 0.41 & 0.40 & 0.54 & 0.45 & 0.48 \\
\hline BIAS & 0.79 & 0.50 & 0.41 & 0.60 & 0.41 & 0.18 & 0.45 & 1.09 & 0.77 & 0.58 & 0.51 & 0.17 & 0.00 & 0.06 \\
\hline MDE & 0.31 & 0.48 & 0.55 & 0.45 & 0.59 & 0.67 & 0.55 & 0.34 & 0.37 & 0.50 & 0.55 & 0.65 & 0.78 & 0.73 \\
\hline
\end{tabular}

To assess overall performance in order to determine best model configurations, the mean absolute distance error (MDE) is defined by

$$
\mathrm{MDE}=\frac{(1-\mathrm{CS})+\operatorname{abs}(1-\mathrm{BIAS})}{2}
$$

where $\operatorname{abs}(x)$ means the absolute value of $x$. Note that the MADE value closest to 1 is the perfect skill score, and MDE measures the average magnitude of the absolute difference between model skill scores and the value 1 , of which the combined score and BIAS represent the perfect skill and unbiased score. Thus, the smaller value of MDE indicates the better model predictability.

The purposes of the MDE score were to understand the overall performance better and summarize the results for a final decision. The overall ranking of the model simulations for the wet season showed that the default simulation (simulation 1) was first, followed by simulation 2, and simulation 6 showed the poorest skill. For the dry season, the overall ranking of the model simulations showed that simulation 1 was first, followed by simulation 2. Meanwhile, simulation 6 and simulation 7 showed the poorest skill because the FAR index was not assessable for these simulations due to a large number of false alarms.

\section{Conclusions and Remarks}

The performance of different schemes on the precipitation systems during the wet and dry seasons over Tanzania is evaluated in this study. Tanzania is located in the tropics, where during the wet season, the dominant weather system is the ITCZ, which produces deep convective systems, including thunderstorms. During the dry season, weather systems dominating the country are mainly stratiform, which occupy a large area and are not affected by local features such as topography and land cover. In order to evaluate the skill of the model predictability for different resolutions and various parameterizations, each model simulation was ranked based on the statistical indexes explained in the above section. For each index, the simulations were ranked for each season, and then the average rank of each simulation was calculated based on all the statistical indexes combined. 
Generally, all the resolution settings, which were 15/5, 12/4, and 9/3 km grid spacing, showed reasonably good forecasting in terms of special coverage of the rainfall systems. Increased resolution (i.e., $9 / 3 \mathrm{~km}$ grid spacing) showed a greater improvement in the special coverage than the low-resolution simulations (i.e., $15 / 5 \mathrm{~km}$ grid spacing), especially during the wet season when the weather system was dominated by convective systems [32]. Convective systems occur in small areas and are highly influenced by local features, such as topography and land cover; thus, the higher resolution models are better at predicting predominantly convective weather systems. For the dry season, there was no visible pattern regarding the improvement in the skill of the model, as the model resolution was increased over Tanzania. As noted above, the dominant weather systems during the dry seasons are stratiform in nature, which always occupy relatively large area thus not being affected by local scale features. Thus, increased resolution had little impact in predicting stratiform systems.

The default simulation containing the Lin et al. microphysics scheme with the multiscale Kain-Fritsch cumulus physics scheme showed greater success at resolving weather systems during the wet season. The microphysics scheme is able to take into consideration the deep convective systems and clouds in all phases, i.e., liquid, ice, and vapor processes; in this research, it was also proved to be better at resolving weather systems during the wet season. Following the findings of this study, it is recommended that the findings of this research be adopted for operational forecasting at the TMA. In addition, further research should be conducted with other physical parameterizations, such as radiation physics and planetary boundary layer physics, among others. Even with these findings, further research should be conducted to improve the physical equations and better resolve the weather systems in the country and the region as a whole.

Author Contributions: A.L. and S.K. conceived and designed the experiments and wrote the paper. G.C. and M.J. analyzed the data. M.J. visualized the data. Y.K. edited the paper. All authors have read and agreed to the published version of the manuscript.

Funding: This work was supported by a 2-Year Research Grant of Pusan National University.

Acknowledgments: The authors thank the editor and reviewers who provided constructive and thoughtful comments to improve this paper.

Conflicts of Interest: The authors declare no conflict of interest.

\section{References}

1. Kijazi, A.L.; Reason, C.J.C. Relationships between intraseasonal rainfall variability of coastal Tanzania and ENSO. Theor. Appl. Climatol. 2005, 82, 153-176. [CrossRef]

2. Ogallo, L. Rainfall variability in Africa. Mon. Weather Rev. 1979, 107, 1133-1139. [CrossRef]

3. Futyan, J.M.; Del Genio, A.D. Deep convective system evolution over Africa and the tropical Atlantic. J. Clim. 2007, 20, 5041-5059. [CrossRef]

4. Kijazia, A.L.; Reasona, C.J.C. Analysis of the 2006 floods over northern Tanzania. Int. J. Climatol. 2009, 29, 955-970. [CrossRef]

5. Skamarock, W.C.; Klemp, J.B.; Dudhia, J.; Gill, D.O.; Barker, D.O.; Wang, W.; Powers, J.G. A Description of the Advanced Research WRF Version 3; Technical Report; National Center for Atmospheric Research: Boulder, CO, USA, 2005; p. 113. [CrossRef]

6. Kain, J.S. The Kain-Fritsch convective parameterization: An update. J. Appl. Meteorol. 2004, 43, 170-181. [CrossRef]

7. Zheng, Y.; Alapaty, K.; Herwehe, J.A.; Genio, A.D.D. Improving High-Resolution Weather Forecasts Using the Weather Research and Forecasting (WRF) Model with an Updated Kain-Fritsch Scheme. Mon. Weather Rev. 2016, 144, 833-860. [CrossRef]

8. Hong, S.-Y.; Noh, Y.; Dudhia, J. A new vertical diffusion package with an explicit treatment of entrainment processes. Mon. Weather Rev. 2006, 134, 2318-2341. [CrossRef]

9. Lin, Y.L.; Farley, R.D.; Orville, H.D. Bulk parameterization of the snow field in a cloud model. J. Clim. Appl. Meteorol. 1983, 22, 1065-1092. [CrossRef] 
10. Tewari, M.; Chen, F.; Wang, W.; Dudhia, J.; LeMone, M.A.; Mitchell, K.; Ek, M.; Gayno, G.; Wegiel, J.P.; Cuenca, R.H.; et al. Implementation and verification of the unified noah land surface model in the WRF model. Bull. Am. Meteorol. Soc. 2004, 27, 2165-2170. [CrossRef]

11. Mlawer, E.J.; Taubman, S.J.; Brown, P.D.; Iacono, M.J.; Clough, S.A. Radiative transfer for inhomogeneous atmospheres: RRTM, a validated correlated-k model for the longwave. J. Geophys. Res. Atmos. 1997, 102, 16663-16682. [CrossRef]

12. NCEP. The GFS Atmosphere Model; Note 442; (November); NCEP: Washington, DC, USA, 2003; p. 14. Available online: http://www.emc.ncep.noaa.gov/officenotes/newernotes/on442.pdf (accessed on 1 May 2020).

13. Lim, K.-S.S.; Hong, S.-Y. Development of an effective double-moment cloud microphysics scheme with prognostic cloud condensation nuclei (CCN) for weather and climate models. Mon. Weather Rev. 2010, 138, 1587-1612. [CrossRef]

14. Janjić, Z.I. The Step-Mountain Eta Coordinate Model: Further developments of the convection, viscous sublayer, and turbulence closure schemes. Mon. Weather Rev. 1994, 927-945. [CrossRef]

15. Grell, G.A.; Freitas, S.R. A scale and aerosol aware stochastic convective parameterization for weather and air quality modeling. Atmos. Chem. Phys. 2014, 14, 5233-5250. [CrossRef]

16. Grell, G.A.; Dévényi, D. A generalized approach to parameterizing convection combining ensemble and data assimilation techniques. Geophys. Res. Lett. 2002, 29, 38-1-38-4. [CrossRef]

17. Han, J.; Pan, H.-L. Revision of convection and vertical diffusion schemes in the NCEP Global Forecast System. Weather Forecast. 2011, 26, 520-533. [CrossRef]

18. Hong, S.-Y.; Dudhia, J.; Chen, S.-H. A revised approach to ice microphysical processes for the bulk parameterization of clouds and precipitation. Mon. Weather Rev. 2004, 132, 103-120. [CrossRef]

19. Hong, S.; Lim, J. The WRF single-moment 6-class microphysics scheme (WSM6). J. Korean Meteorol. Soc. 2006, 42, 129-151.

20. Pan, H.-L.; Wu, W.-S. Implementing a mass flux convective parameterization package for the NMC medium-range forecast model. NMC Off. Note. 1995, 409. Available online: https://repository.library.noaa. gov/view/noaa/11429 (accessed on 1 May 2020).

21. Tiedtke, M.A. Comprehensive mass flux scheme for cumulus parameterization in large-scale models. Mon. Weather Rev. 1989, 117, 1779-1800. [CrossRef]

22. Zhang, C.; Wang, Y.; Hamilton, K. Improved representation of boundary layer clouds over the southeast Pacific in ARW-WRF using a modified Tiedtke cumulus parameterization scheme. Mon. Weather Rev. 2011, 139, 3489-3513. [CrossRef]

23. Kain, J.S.; Fritsch, J.M. Multiscale convective overturning in mesoscale convective systems: Reconciling observations, simulations, and theory. Mon. Weather Rev. 1998, 126, 2254-2273. [CrossRef]

24. Pearson, K. On the Theory of Contingency and Its Relation to Association and Normal Correlation; Drapers' Company Research Memoirs Biometric Series I; Cambridge University Press: Cambridge, UK, 1904.

25. Rodrigo, C.; Kim, S.; Jung, I.H. Sensitivity study of WRF numerical modeling for forecasting heavy rainfall in Sri Lanka. Atmosphere 2018, 9, 378. [CrossRef]

26. Taylor, K.E. Summarizing multiple aspects of model performance in a single diagram. J. Geophys. Res. 2001, 106, 7183-7192. [CrossRef]

27. Dawson, A.; Palmer, N.T. Simulating weather regimes: Impact of model resolution and stochastic parameterization. Clim. Dyn. 2015, 44, 2177-2193. [CrossRef]

28. Rolfova, Z.; Farda, A.; Kysely, J. Effects of Horizontal Resolution of Regional Climate Model Simulations on Convective and Stratiform Precipitation. In Proceedings of the 14th EMS Annual Meeting Abstracts, Prague, Czech Republic, 6-10 October 2014.

29. Ebert, E.E.; Damrath, U.; Wergen, W.; Baldwin, M.E. The WGNE assessment of short-term quantitative precipitation forecasts. Bull. Am. Meteorol. Soc. 2003, 84, 481-492. [CrossRef]

30. Jang, J.; Hong, S.Y. Quantitative forecast experiment of a heavy rainfall event over Korea in a global model: Horizontal resolution versus lead time issues. Meteorol. Amos. Phys. 2014, 124, 113-127. [CrossRef] 
31. Jee, J.B.; Kim, S. Sensitivity study on high-resolution numerical modeling of static topographic data. Atmosphere 2016, 7, 86. [CrossRef]

32. Wang, X.; Steinle, P.; Seed, A.; Xiao, Y. The sensitivity of heavy precipitation to horizontal resolution, domain size, and rain rate assimilation: Case studies with a convection-permitting model. Adv. Meteorol. 2016, 1-20. [CrossRef] 